\title{
EL NUEVO CRITERIO DE «LA TUTELA MATERIALMENTE EQUIVALENTE» EN RELACIÓN CON LAS EXPROPIACIONES LEGISLATIVAS (LA STC 48/2005)
}

FERNANDO REY MARTÍNEZ

Profesor Titular de Derecho Constitucional

Universidad de Valladolid

SUMARIO

I. Introducción: la importancia de la STC $48 / 2005$ radica en que se trata de la primera decisión en la que el Tribunal Constitucional estima vulnerado el derecho constitucional de propiedad privada y en que reduce a márgenes muy estrechos el ámbito posible de las expropiaciones ope legis.

II. Análisis: los hechos y los argumentos del Tribunal.

III. Comentario: el criterio de la "tutela materialmente equivalente" revoca la doctrina "Rumasa" sobre expropiaciones legislativas de caso único, pero es dudoso que pueda leerse como un giro garantista del Tribunal en la interpretación del derecho de propiedad privada. 


\section{INTRODUCCIÓN: LA IMPORTANCIA DE LA STC 48/2005 RADICA EN QUE SE TRATA DE LA PRIMERA DECISIÓN EN LA QUE EL TRIBUNAL CONSTITUCIONAL ESTIMA VULNERADO EL DERECHO CONSTITUCIONAL DE PROPIEDAD PRIVADA Y EN QUE REDUCE A MÁRGENES MUY ESTRECHOS EL ÁMBITO POSIBLE DE LAS EXPROPIACIONES OPE LEGIS}

La STC 48/2005 resuelve una cuestión de inconstitucionalidad promovida por la Sala de lo Contencioso-Administrativo del Tribunal Superior de Justicia de Canarias en relación con la Ley del Parlamento de Canarias 2/1996, de 26 de junio, sobre declaración de utilidad pública de la expropiación forzosa de diversos edificios de Santa Cruz de Tenerife para proceder a la ampliación de la sede del Parlamento de Canarias, por supuesta vulneración de las garantías expropiatorias previstas en el tercer apartado del artículo 33 CE. Esta Sentencia, cuyo ponente ha sido la Presidenta del Tribunal, D. ${ }^{a}$ M. ${ }^{a}$ Emilia Casas, ampara, por primera vez en toda la jurisprudencia del Tribunal Constitucional, los derechos de los propietarios. Empleando un astringente examen de proporcionalidad de la expropiación legislativa singular, concluye que la ley impugnada habría violado el art. 33.3 CE. La desproporción de la expropiación ope legis deriva de que el poder público expropiante podría haber llegado a un acuerdo con los propietarios de los inmuebles anejos al Parlamento, podría haber expropiado otros inmuebles y no precisamente esos, o podría haber procedido a una expropiación administrativa ordinaria que no hubiera privado a los propietarios de la posibilidad de discutir en sede judicial con el expropiante tanto la causa de la expropiación como la declaración de la necesidad de ocupación de los tres inmuebles concretos relacionados en el artículo primero de la Ley.

Se trata, a mi juicio, de una saludable Sentencia, que es significativa por dos razones. Primera, porque es la primera vez que el Tribunal Constitucional estima vulnerado el derecho de propiedad privada, concretamente respecto de la garantía del procedimiento expropiatorio (art.33.3 CE). Más de un cuarto de siglo ha necesitado el Tribunal para "descubrir" el hasta ahora vergonzante y anoréxico derecho dominical. Lo cierto es que, como tendremos ocasión de comprobar, el caso era bastante claro y se prestaba abiertamente a ello. Segunda, porque el Tribunal endurece aún más las estrictas condiciones de adecuación a la Constitución de las leyes expropiatorias singulares; en realidad, lo hace de tal modo que si se aplicara la interpretación que realiza en esta Sentencia 48/2005 al célebre caso "Rumasa" (que originó cuatro pronunciamientos del Tribunal Constitucional, el leading-case de las expropiaciones legislativas se halla en la Sentencia 166/1986, "Rumasa/dos"), su fallo en aquella ocasión hubiera sido diametralmente opuesto, por lo que la STC 48/2005 viene a revocar la doctrina de la Sentencia "Rumasa/dos". La STC 48/2005 "exorciza" definitivamente el "fantasma" Rumasa en uno de sus aspectos principales.

La tesis principal de este trabajo es que la doctrina de esta Sentencia perdurará más por su lectura restrictiva de las expropiaciones ope legis (que, por 
fortuna, tampoco se prodigan en nuestro ordenamiento, quizás porque recae sobre su validez una sospecha generalizada - la misma que recibe la solución dada al asunto Rumasa), que por un cambio en la "política de derechos fundamentales" del Tribunal en el sentido de ponerse más serio en la protección del derecho de propiedad privada. De hecho, en la Sentencia 48/2005 en ningún momento aparece el derecho de propiedad como un argumento central de la resolución del caso $^{1}$. Aunque, curiosamente, cuando el Tribunal vuelca en la Sentencia la interpretación que el Tribunal de Estrasburgo ha venido haciendo del art. 1 del Protocolo Adicional — de un modo un tanto discutible e innecesario, por lo demás-, sí recuerda cómo dicho Tribunal vincula —como es lógico- las garantías del procedimiento expropiatorio al reconocimiento general del derecho de propiedad. Así pues, la STC 48/2005 marca un "antes" y un "después" en la interpretación de las leyes expropiatorias singulares, pero no imprime - me atrevo a adivinar - un giro copernicano en la interpretación del derecho de propiedad privada, a pesar de ser —insisto- la primera Sentencia del Tribunal en toda su ya larga historia que ampara los derechos dominicales frente a un acto del poder público. Y, por consiguiente, me parece que esta Sentencia, a pesar de que una lectura superficial de la misma pudiera inducir una opinión distinta, está llamada a ser más "episódica" que "epocal" en la interpretación por parte del Tribunal Constitucional del art. 33 CE.

En otros lugares ${ }^{2}$ he intentado explicar las razones de la contumaz y anacrónica devaluación que sufre el derecho de propiedad privada en nuestro ordenamiento a pesar de que es, huelga casi decirlo por obvio, un elemento central de las disposiciones constitucionales sobre la economía y del propio orden social. Tanto, que siempre he sostenido que se trata de un auténtico derecho fundamental y no "sólo" de un principio, de una garantía de instituto, de un derecho debilitado, etc. Esta tesis fue minoritaria en su momento, pero me parece advertir en la literatura actual un cambio de tendencia.

La propiedad en el Estado social no es ya la propiedad de los Códigos Civiles decimonónicos, no es la propiedad de John Locke — que es la misma del Robinson Crusoe de Daniel Defoe, de educación puritana y militante whig como aquél, que imagina un Robinson Crusoe en 1719 como un héroe burgués capaz de vencer todo tipo de dificultades y de edificar un paraíso de civilización en la tierra. Robinson Crusoe es el "hombre nuevo" que preconiza la Ilustración y si la isla es el estado de naturaleza que el iusnaturalismo moderno utilizó para

1 Sí se recurre, como es natural, al rutinario y esquemático recuerdo de la doctrina de la naturaleza de la expropiación como garantía de los propietarios, pero nada más.

2 Permítaseme la remisión al libro La propiedad privada en la Constitución española, CEC/BOE, Madrid, 1994, y a algunos trabajos de actualización, como: "Sobre la (paradójica) jurisprudencia constitucional en materia de propiedad privada", Derecho Privado y Constitución, n. ${ }^{\circ}$, 1994, págs. 169 y ss.; la voz "Derecho de propiedad privada" en el Diccionario Jurídico Civitas, Madrid, 2000, tomo III, págs. 203-215; y el capítulo del libro Propiedad y Derecho Constitucional (coord. F. Bastida, Centro de Estudios del Colegio de Registradores de la Propiedad y Mercantiles de España, Madrid, 2005), titulado "El devaluado derecho fundamental de propiedad privada" (pp. 195228). 
elaborar su teoría política, Robinson Crusoe significa el triunfo civil sobre la naturaleza. El título que esgrime sobre la isla es su trabajo, el fundamento lockeano de la propiedad privada: el verdadero ciudadano es el burgués trabajador, diligente... propietario ${ }^{3}$.

En la Constitución del Estado social y democrático de Derecho, por el contrario, la justificación de la propiedad no estrictamente personal descansa en que debe reconocerse no sólo el derecho "de" propiedad sino también el derecho "a la" propiedad de toda persona, es decir, debe ser accesible a todos y su ejercicio debe regularse de acuerdo con la función social que cumplan los concretos bienes que constituyan su objeto. De modo que el discurso sobre la función social de la propiedad y su accesibilidad, "real y efectiva" se convierte en el corazón del problema de la justificación constitucional de la propiedad privada no personal. En otras palabras, la atribución constitucional del derecho a la propiedad privada únicamente tiene sentido si a cada persona se le asegura una cierta cantidad (suficiente para desarrollar de modo autónomo la propia existencia y para participar activamente como ciudadano) de propiedad.

Este cambio de paradigma en la comprensión del derecho de propiedad privada no ha acabado de triunfar en la cultura jurídica dominante española. Sobre la interpretación común del derecho de propiedad pesan no pocos factores devaluadores y, entre ellos, sobresale el prejuicio ideológico, pues ninguna corriente de pensamiento político se siente del todo cómoda en relación con este derecho que, paradójicamente, parece un bien mostrenco porque nadie quiere ser (ideológicamente) su dueño. Las añejas reservas ideológicas contra la propiedad privada se reflejan, lógicamente, en el plano jurídico. En efecto, en la treintena de Sentencias en las que se ha referido al derecho de propiedad, el Tribunal Constitucional se ha hecho eco de las transformaciones que ha experimentado la concepción liberal-individualista de la propiedad, manifestada, ante todo, en el Código Civil, pero su jurisprudencia está marcada por un intenso signo degradador de la garantía constitucional dominical. Dos causas principales explican, quizás, este hecho, una concreta y otra general.

La primera es, precisamente, el importante asunto de la expropiación, mediante Real Decreto-ley 2/1983, de 23 de febrero, del grupo de empresas RU-

3 Ver, en este sentido, el delicioso estudio de J. M. Lasalle Ruíz: John Locke y los fundamentos modernos de la propiedad, Universidad Carlos III y editorial Dykinson, Madrid, 2001. No obstante, no hay que olvidar que, en la tradición liberal, el modelo lockeano-kantiano de propiedad de finales del siglo xVIII y comienzos del siglo xIx, dio paso al modelo hegeliano-pandectista, que, como consecuencia de la primera Revolución industrial y la emergencia de la empresa, separa la propiedad del trabajo personal (porque ya no sirve para explicar por qué, en la nueva organización del trabajo, una persona se apropia de los resultados del trabajo de otra) y transita del iusnaturalismo al positivismo jurídico (vid. "La propiedad privada...", ob.cit., págs. 60-68). La propiedad "capitalista" de finales del XIX no está en pugna con las tesis feudales, sino con las socialistas; la propiedad — dice ahora Windscheid - "es ilimitada", aunque admita restricciones. Según Hegel, las cosas no son más que la prolongación de la voluntad de su dueño. Esta definición formal, abstracta, idealista (y profundamente conservadora) se adaptaba como un guante a las necesidades de crecimiento del capitalismo de la época. 
MASA. Sostener la adecuación a la Constitución de tan (desproporcionada en mi opinión,) medida ha hipotecado, en gran medida, la línea jurisprudencial posterior del Tribunal.

La causa general de la jurisprudencia devaluadora de la propiedad constitucional es, sin duda, el arraigo que en la cultura jurídica española posee la concepción de la propiedad, prototípicamente la urbana, como un derecho de exclusiva configuración legislativa, ante el que la Constitución poco o nada tendría que decir, salvo, claro está, por lo que se refiere a la última (y casi única) barrera de protección, la garantía expropiatoria, por cierto también muy debilitada a su vez. Según esta interpretación, que se fundamenta en una comprensión quizás excesivamente potente de la idea de la función social, el derecho de propiedad del art. 33 CE no sería en rigor un derecho fundamental, sino, a lo sumo, una simple especificación en el ámbito del derecho patrimonial del principio de legalidad de la actividad administrativa, pues su reconocimiento constitucional no tendría más efecto que el de una remisión al legislador ordinario para que éste determine por entero el estatuto jurídico correspondiente a cada tipo de bien, con atención preferente a su utilidad social, y, desde luego, no tendría apenas contenido ex Costitutione oponible frente a los poderes públicos. De hecho, en ninguno de los recursos que había venido resolviendo sobre esta materia el Tribunal Constitucional hasta la STC 48/2005 había estimado que se hubiera violado el derecho de propiedad. En esta misma dirección se mueve la jurisprudencia del Tribunal Supremo, para quien el art. 33 CE sería un precepto "escasamente innovador" (STS, de 27 de octubre de 1979 -R.A. 3543-), pues no vendría a añadir apenas nada a la interpretación anterior a la Constitución del derecho de propiedad, que ya habría ido transformado la concepción dominical civilista. Concepción ésta que también sigue contando con partidarios, de modo que en la doctrina española conviven, ignorándose mutuamente, el modelo clásico o "privado" de propiedad que sigue residenciando en el Código Civil el régimen fundamental dominical y el modelo administrativo, urbanístico o "público" de propiedad, antes aludido. Ambos modelos vienen a coincidir en la afirmación de la carencia de un contenido constitucionalmente garantizado de la propiedad, salvo un cada vez más devaluado instituto expropiatorio, que se concibe más como "potestad" a favor de la Administración que como "garantía" de los administrados. En la Sentencia 48/2005 el Tribunal Constitucional se inclina, sin embargo, a favor de estos últimos, lanzando, por primera vez, un claro y perdurable mensaje contra los desequilibrios y excesos en que pueda incurrir la potestad pública expropiatoria.

A continuación analizaré los hechos y argumentos vertidos en la Sentencia $y$, desde ese examen, intentaré justificar por qué entiendo que es más "episódica" que "epocal»".

4 Entiendo por "episódica" una Sentencia cuya doctrina sólo ha servido para resolver un asunto, pero no otros posteriores, por contraposición a las "epocales", que serían aquellas que des- 


\section{ANÁLISIS: LOS HECHOS Y LOS ARGUMENTOS DEL TRIBUNAL}

La Ley cuestionada tiene dos artículos. En el primero se dispone que, para ampliar la sede del Parlamento de Canarias, se declara de utilidad pública la expropiación forzosa de tres edificios concretos, contiguos a la sede actual. En el segundo se habilita al Gobierno de Canarias para que, a instancia de la Mesa del Parlamento regional, previa audiencia de la Junta de Portavoces, pueda declarar la utilidad pública de otros inmuebles colindantes al de la sede de la Cámara, también a los efectos de su ampliación. El Gobierno de Canarias dictó un reglamento de ejecución de la Ley, el Decreto 142/1993, de 30 de abril, por el que se declaraba urgente la ocupación de los bienes y derechos afectados por la expropiación iniciada por la Consejería de Economía y Hacienda con motivo de la ampliación de la sede del Parlamento autonómico. En el marco de sendos procedimientos contencioso-administrativos acumulados contra tal Decreto, el órgano judicial a quo decidió elevar la cuestión de inconstitucionalidad ante el Tribunal Constitucional en la medida en que, correctamente, consideró que el Decreto traía causa directa de la Ley.

Las dudas de constitucionalidad de la Ley canaria por parte del órgano judicial ordinario en relación con el art. 33.3 CE se contrajeron a tres:

1. a) La Ley cuestionada es una ley expropiatoria singular dictada para hacer frente no a una situación singular, sino general u ordinaria (la ampliación de la sede del Parlamento territorial con unos inmuebles sobre los que no se ha llegado a un acuerdo amistoso con sus titulares), que justificaría, en su caso, la utilización de la potestad expropiatoria ordinaria por parte de la Administración. Esto violaría el art. 33.3 CE cuando ordena que la expropiación se realice "de conformidad con lo dispuesto por las leyes" (garantía del procedimiento expropiatorio).

2. ${ }^{a}$ El recurso a leyes expropiatorias sólo resulta constitucionalmente admisible en supuestos excepcionales que, por su extraordinaria trascendencia y complejidad, no son remediables por las técnicas expropiatorias normales de las que dispone la Administración. Pues bien, la Ley cuestionada afronta "una situación nada fuera de lo corriente" y, al hacerlo de este modo, priva a los expropiados de las garantías que les confiere el procedimiento ordinario de expropiación.

3. ${ }^{a}$ En consecuencia, la Ley es desproporcionada en atención a la causa expropiandi, utilidad pública o interés social, y a la necesidad de ocupación de los bienes y derechos.

plegarían una influencia posterior, marcando un tiempo o época nuevas en la interpretación del Tribunal de alguna materia (bien por convertirse en leading-cases, bien por contener una doctrina especialmente relevante, bien por resolver un asunto público de significativa trascendencia). 
Tanto el Abogado del Estado 5 como los Letrados del Parlamento y del Gobierno de Canarias ${ }^{6}$ solicitaron del Tribunal Constitucional la desestimación de la cuestión de inconstitucionalidad planteada, en tanto que el Fiscal General del Estado interesó, por el contrario, su estimación ${ }^{7}$.

Podemos sintetizar el razonamiento del Tribunal Constitucional del siguiente modo:

A) Con carácter previo, la Sentencia analiza dos argumentos procesales, (a) la incidencia que pudiera tener en este caso la doctrina establecida por el Tribunal Europeo de Derechos Humanos en su Sentencia de 23 de junio de 1993, asunto Ruiz Mateos c. España, y (b) la determinación del objeto de la cuestión (esto es, de las disposiciones legales cuestionadas y de las constitucionales de contraste), y dos argumentos de fondo generales, (c) los perfiles constitucionales del instituto expropiatorio y (d) de las leyes expropiatorias en particular, según la doctrina anterior establecida por el Tribunal Constitucional.

5 El Abogado del Estado efectuó las siguientes alegaciones: (1. ${ }^{\circ}$ La Ley canaria no era, en realidad, una Ley expropiatoria singular porque no producía directamente el efecto ablatorio, la privación del bien (aparte del acuerdo de necesidad de la ocupación, estaríamos en presencia de una expropiación administrativa ordinaria; en particular, la garantía indemnizatoria de los expropiados está regulada por las normas comunes y es revisable por la jurisdicción contencioso-administrativa). (2. ${ }^{\circ}$ En nuestro ordenamiento, la declaración de utilidad pública se puede hacer por ley o por el órgano administrativo habilitado con base en una ley. Y no hay razones para negar que la ampliación de un Parlamento sea de utilidad pública. (3. ) El acuerdo de necesidad de ocupación sí es, ordinariamente, un acto administrativo, precisamente el que abre el procedimiento expropiatorio, pero no es inconstitucional que pueda adoptarlo directamente una Ley, como es el caso, porque la Constitución no reserva a la Administración la determinación de los bienes de necesaria ocupación en una expropiación y porque respecto de la Ley cuestionada existiría un nexo especialmente intenso entre el fin de la expropiación y los bienes necesarios para conseguir el fin.

6 El Letrado del Parlamento de Canarias opuso los siguientes argumentos (que hizo suyos el Letrado del Gobierno regional): (1. ${ }^{\circ}$ ) El Letrado coincide con los argumentos del Abogado del Estado que he expuesto en los números primero y tercero (la justificación de la causa expropiandiampliación de la sede parlamentaria - conllevaría necesariamente la concreción de los bienes a expropiar - los inmuebles contiguos-) de la nota anterior. (2. ${ }^{\circ}$ Por otro lado, la autonomía parlamentaria lleva a que la cuestión de la fijación de la sede parlamentaria sea asumida directamente por la propia Cámara, sin conceder un ámbito de decisión en este asunto al poder ejecutivo regional. (3..$^{\circ}$ La Ley sería proporcionada porque la ampliación de la sede es razonable (dadas las carencias de espacio actuales) y porque el modo en que se propone responde a una solución técnica arquitectónica adecuada con la finalidad perseguida.

7 El Fiscal General del Estado siguió, en líneas generales, la argumentación de la Sala que presentó la cuestión de inconstitucionalidad, razonando que la declaración de la utilidad pública de la ampliación de la sede parlamentaria es razonable, pero no lo es el empleo para un supuesto de hecho ordinario del medio excepcional que supone la ley expropiatoria de caso único. Concretamente, la determinación por ley de la necesidad de ocupación de ciertos bienes supone para los expropiados la imposibilidad de discutir ante los Tribunales ordinarios uno de los aspectos esenciales de la expropiación, con evidente limitación del acceso a la jurisdicción (art. 24.1 CE). También se lesiona el principio de igualdad (art. $14 \mathrm{CE}$ ) porque atribuye a los expropiados de este modo una peor condición de la que gozan los demás sujetos cuyos bienes sólo pueden ser expropiados conforme al procedimiento general. No concurre en el caso ningún factor de excepcionalidad que impida objetivamente al órgano expropiante a utilizar el cauce ordinario. 
a) Según la conocida doctrina del Tribunal europeo, dado que la Ley enjuiciada es una ley singular, sus destinatarios deberían haber sido parte en este procedimiento. El Tribunal Constitucional confirma, pues, que la Ley impugnada es una Ley singular (en contra de la tesis presentada por el Abogado del Estado y por el Letrado del Parlamento de Canarias) y que es la primera vez, desde el asunto Rumasa, que vuelve a enjuiciar una norma de este carácter, por lo que la doctrina de la Sentencia del Tribunal de Estrasburgo sería, en principio, aplicable a este caso. Pero también constata que la regulación de la LOTC sigue siendo la misma que motivó la condena al Estado español del Tribunal europeo, aunque advierte que el Tribunal Constitucional habría estado dispuesto a "flexibilizar el tenor de nuestra Ley rectora" (por "consideraciones inaplazables de defensa de los derechos fundamentales", sobre todo cuando "su infracción ha sido formalmente constatada por el Tribunal Europeo de Derechos Humanos"), siempre, eso sí, que los interesados hubieran pretendido la personación en el procedimiento, lo que no se produjo.

Así pues, la Sentencia advierte que el legislador orgánico español sigue sin cumplir sus deberes tras la Sentencia Rumasa del Tribunal europeo, esto es, sin modificar la arquitectura del procedimiento de la cuestión de inconstitucionalidad en el sentido indicado para hacerlo compatible con el derecho de defensa y de igualdad de armas, aunque anuncia a posteriori una atípica "flexibilización", no amparada legalmente y por ello de muy dudosa naturaleza. Si los recurrentes en el proceso ordinario, es decir, los expropiados por la Ley canaria, hubieran perdido el caso ante el Tribunal Constitucional (como le ocurrió a Ruiz-Mateos entonces) y hubiesen acudido a Estrasburgo, con seguridad habría recaído otra condena contra el Estado español por el mismo motivo que la del año 1993.

b) En cuanto a la determinación del objeto de la cuestión de inconstitucionalidad, el Tribunal concluye que la disposición cuestionada sólo puede ser el artículo primero de la Ley, pero no el segundo, porque sólo el primero supera el juicio de relevancia, y que la norma constitucional de contraste invocada por el Tribunal a quo es solamente el art. 33.3 CE, sin perjuicio de que el Tribunal Constitucional pueda fundar su juicio de constitucionalidad en cualquier otro precepto constitucional en la medida en que resulte necesario.

c) Entrando ya en el fondo del asunto, pero aún con carácter general y previo, la Sentencia recuerda su doctrina sobre la configuración constitucional del instituto expropiatorio (asunto que, por cierto, me parece que podría haber perfectamente omitido porque no añade nada nuevo a su juicio y lo único que hace es espesar innecesariamente la argumentación). El iter argumental es de sobra conocido:

1..$^{\circ}$ La expropiación forzosa, en cuanto límite excepcional del derecho a la propiedad privada ha sufrido una transformación desde su origen en el Estado liberal hasta el actual Estado social (de límite negativo de los poderes públicos a instrumento puesto a su disposición para cumplir la justicia social). 
2..$^{\circ}$ Es potestad, ordinariamente, de la Administración, aunque el legislador puede ejercitarla singularmente cuando lo justifique una situación excepcional y si respeta las garantías del art. 33.3 CE.

3. ${ }^{\circ}$ Tiene una doble naturaleza, como técnica destinada a la consecución de intereses públicos y como garantía de la propiedad privada.

$4^{\circ} .^{\circ}$ En este último sentido, el art. 33.3 CE establece una triple garantía: causa expropiandi, correspondiente indemnización y conformidad a lo dispuesto en las leyes.

Una novedad de esta Sentencia es que incorpora un resumen del sistema del Convenio de Roma en esta materia, aunque España ha firmado una reserva al artículo primero del Protocolo Adicional (el cual reconoce el derecho de propiedad de un modo más o menos equivalente a nuestro artículo $33 \mathrm{CE}$ ). Hay que llamar la atención sobre el hecho de que el Tribunal Constitucional va a utilizar ese precepto europeo y la jurisprudencia que lo interpreta y aplica, a pesar de la expresa reserva mencionada (reserva, por cierto, que intentó apagar la extensión del ominoso incendio "Rumasa" al entorno europeo), lo cual no deja de resultar un tanto excesivo, aunque se traiga a colación sólo como argumento de refuerzo, perfectamente redundante ${ }^{8}$.

d) La última parte de la introducción es la evocación de la doctrina del Tribunal sobre las expropiaciones legislativas en particular, contenida en la Sentencia 166/1986, la segunda sentencia del caso Rumasa:

1. $\left.{ }^{\circ}\right)$ Las expropiaciones ope legis deben respetar las garantías del art. 33.3 $\mathrm{CE}$, esto es, deben responder a una finalidad de utilidad pública o interés social (causa expropiando), deben garantizar la correspondiente indemnización y deben respetar lo dispuesto en las leyes.

2. ${ }^{\circ}$ En relación con esta última garantía, denominada por el Tribunal como "garantía del procedimiento expropiatorio" y que ha deducido de la expresión "de conformidad con lo dispuesto por las leyes" del art. 33.3 CE, el Tribunal Constitucional ha afirmado lo siguiente:

I. Se establece en beneficio de los ciudadanos y tiene por objeto proteger sus derechos a la igualdad y a la seguridad jurídica, estableciendo el respeto y sumisión a normas generales de procedimiento legalmente preestablecidas.

II. En cuanto aplicación específica del principio de legalidad en materia de expropiación forzosa, va dirigida principalmente frente a la Administración y, en razón de ello, puede sostenerse que las leyes formales, incluidas las singulares, cubren por sí mismas esa garantía, cualquiera que sea el procedimiento que establezcan.

8 Un excelente estudio del artículo primero del Protocolo Adicional puede encontrarse en Mar Aguilera: "El reconocimiento del derecho a la propiedad privada y los límites a su regulación", en $L a$ Europa de los Derechos. El Convenio Europeo de Derechos Humanos (coords.: Javier García Roca y Pablo Santolaya), CEPC, Madrid, 2005, págs. 767-800. 
III. La naturaleza excepcional y singular inherente a las leyes singulares de expropiación no autoriza, sin embargo, al legislador a prescindir de la garantía del procedimiento expropiatorio establecido en las leyes generales de expropiación, al cual deben igualmente someterse. Pero ello no es obstáculo para que la propia singularidad del supuesto de hecho que legitima la expropiación legislativa autorice al legislador para introducir en el procedimiento general las modificaciones que exija tal singularidad excepcional, siempre que se inserten como especialidades razonables que no dispensan de la observancia de las demás normas de los procedimientos contenidos en la legislación general.

IV. Las leyes singulares de expropiación inciden sobre el derecho a la tutela judicial de la propiedad, que el art. 24.1 CE garantiza a todos los propietarios. En efecto, las expropiaciones legislativas son accesibles tan sólo a un control judicial limitado, por cuanto un juicio de constitucionalidad negativo únicamente puede llevar al Juez ordinario a plantear una cuestión de inconstitucionalidad ante el Tribunal Constitucional, en cuya sustanciación no tiene intervención (inmediata) el particular afectado. Es evidente que éste ve mermada la posibilidad de discutir en Derecho el contenido de la decisión formalizada bajo la cobertura de la ley, pues contra ella no podría reaccionar del mismo modo que frente a una actuación administrativa. En el caso planteado por la cuestión en examen, por ejemplo, a los expropiados se les priva de la posibilidad de invocar ante la jurisdicción la existencia de otros bienes capaces de proveer a la necesidad del expropiante en la misma o mejor medida que los que el legislador ha señalado como objeto de expropiación.

El énfasis que pone la Sentencia en este último aspecto (preparando el sentido del fallo) es, acaso, la aportación doctrinal más permanente de esta resolución: las leyes singulares de expropiación sólo son aceptables en la medida en que los intereses y derechos afectados no vean disminuidas su tutela jurisdiccional "de manera sustancial" (fund. jco. 6. ${ }^{\circ}$ ). Y, por consiguiente, "el problema debe abordarse no tanto desde la perspectiva de la forma jurídica de la disposición, cuanto desde el alcance del control jurisdiccional posible sobre la disposición adoptada". En otras palabras, "un acto legislativo expropiatorio sólo será constitucionalmente admisible si el control jurisdiccional que admiten las normas con rango de ley (recurso directo, cuestión y autocuestión de inconstitucionalidad; esta última, previo amparo) es suficiente, en cada caso, para brindar una tutela materialmente equivalente a la que pueda dispensar frente a un acto administrativo un Juez de lo contencioso".

Sin duda, esta nueva perspectiva (que toma, por fin, en serio la garantía del procedimiento expropiatorio) supone un giro garantista en la doctrina del Tribunal sobre las expropiaciones legislativas singulares y una revocación, de hecho, de la doctrina "Rumasa/dos" y un confinamiento de las leyes singulares de expropiación a un ámbito tan excepcional que las convertirá en fenómenos más raros e infrecuentes de lo que ya son en nuestro ordenamiento.

B) A partir de estos fundamentos generales y de esta nueva doctrina, la Sentencia pasa a analizar en concreto la adecuación a Constitución del artículo 
primero de la Ley canaria, concluyendo, como era de esperar, que el razonamiento del Tribunal proponente de la cuestión era correcto, es decir, que no concurren en el caso las circunstancias excepcionales que justificaran una expropiación legislativa singular (con el debilitamiento de garantías aparejado). El recurso a una ley expropiatoria singular es "un medio exorbitante" sólo justificable "cuando los bienes no admitan otra forma de adquisición por el poder público, pero no cuando, como es el caso, éste no puede adquirirlos de manera negociada, supuesto en que la proporcionalidad y la confianza legítima impone más bien servirse de formas jurídicas que, como los actos administrativos, son susceptibles de un control jurisdiccional de mayor alcance y densidad que el ofrecido por el ordenamiento a los particulares frente a las formas con valor de ley".

Pero, además de no venir justificada por circunstancias excepcionales, la Ley recurrida ofrece una estructura y contenido que no permiten que la defensa de los derechos e intereses de los particulares expropiados pueda satisfacerse por el Tribunal Constitucional. El Tribunal examina, en este sentido, dos aspectos:

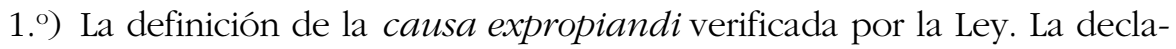
ración de utilidad pública de las obras de ampliación de la sede parlamentaria es plenamente constitucional y no plantea problemas.

2. ${ }^{\circ}$ La declaración de la necesidad de ocupación de los tres inmuebles concretos que menciona el artículo primero de la Ley. Esta declaración, a diferencia de la definición de la causa expropiandi, sí plantea problemas de constitucionalidad porque "para emitir un juicio fundado sobre la posible arbitrariedad o desproporción de (dicha) declaración... son precisos elementos de evaluación que resultan impropios de la jurisdicción de este Tribunal Constitucional".

Llegado el razonamiento a este punto, me parece que la Sentencia podría haber concluido lógicamente con el fallo, sin mayores explicaciones. En el fundamento anterior, el sexto, había establecido la doctrina general (una expropiación ope legis sólo es legítima si todas las lesiones que eventualmente se le imputen puedan ser corregidas por la jurisdicción constitucional), y ahora, en el fundamento séptimo, el Tribunal constata que éste no es el caso (en relación con la declaración de la necesidad de ocupación de tres inmuebles concretos determinados por la Ley), por lo que debería declarar acto seguido la inconstitucionalidad en este punto de la Ley cuestionada. Sin embargo, el Tribunal no hace esto, sino que añade un examen de la proporcionalidad de la medida legal. Tras recordar los tres sub-principios del principio de proporcionalidad (idoneidad, necesidad, proporcionalidad en sentido estricto), y su aplicación por el Tribunal Europeo de Derechos Humanos en relación con el artículo primero del Protocolo Adicional (con menor necesidad aún, a mi juicio, y nuevamente, además, utilizando discutiblemente la vía exegética del art. 10.2 CE sobre un precepto internacional objeto de reserva por parte del Estado espa- 
ñol), la Sentencia concluye que el art. 1 de la Ley canaria lesiona tal principio de proporcionalidad. Concretamente, el Tribunal estima que la expropiación legislativa no es idónea porque los inmuebles que se citan en la Ley no son los únicos que podrían eventualmente permitir la ampliación de la sede parlamentaria (y tampoco explica por qué expropia unos y no otros). Y tampoco es necesaria o indispensable porque puede obtenerse el mismo resultado (la expropiación de determinados inmuebles para la ampliación del Parlamento) recurriendo a un medio menos gravoso de los derechos de los afectados como es la expropiación regulada por las normas generales.

\section{COMENTARIO: EL CRITERIO DE LA «TUTELA MATERIALMENTE EQUIVALENTE" REVOCA LA DOCTRINA "RUMASA" SOBRE EXPROPIACIONES LEGISLATIVAS DE CASO ÚNICO, PERO ES DUDOSO QUE PUEDA LEERSE COMO UN GIRO GARANTISTA DEL TRIBUNAL EN LA INTERPRETACIÓN DEL DERECHO DE PROPIEDAD PRIVADA}

En definitiva, el Tribunal Constitucional hace suya, en los términos descritos, la argumentación tanto del Tribunal Superior de Justicia que cuestiona la Ley canaria, como la del Fiscal General del Estado. El razonamiento y fallo me parecen sustancialmente convincentes, aunque es posible identificar algunos aspectos susceptibles de crítica, como he hecho ya en parte en el epígrafe anterior:

1. ${ }^{\circ}$ El primero de ellos no se refiere tanto al Tribunal, cuanto a su legislador orgánico, que, trece años después, sigue sin adecuar la normativa reguladora de la cuestión de inconstitucionalidad a la doctrina del Tribunal Europeo de Derechos Humanos (asunto Ruiz-Mateos contra España, de 23 de junio de 1993). La solución que ofrece la STC 48/2005 es sólo un atípico parche coyuntural (aunque movido por una loable intención de prevenir un eventual conflicto futuro) y probablemente no hubiera evitado otra condena al Estado español en el caso de que el Tribunal Constitucional no hubiera amparado el derecho de propiedad de los expropiados y éstos hubieran acabado en Estrasburgo.

2. ${ }^{\circ}$ Los fundamentos jurídicos de la Sentencia me parecen excesivamente largos (un mal endémico de la jurisprudencia constitucional) y buena parte de su argumentación innecesaria. Tal ocurre, por ejemplo, con la invocación de la doctrina del Tribunal sobre el instituto expropiatorio en general y, sobre todo, con el recuerdo de la jurisprudencia del Tribunal Europeo de Derechos Humanos que se hace en la Sentencia y que, según creo, no aporta absolutamente nada (además de que el art. 1 del Protocolo Adicional sigue sin estar plenamente vigente en España porque pesa sobre él una reserva — como efecto colateral permanente del asunto Rumasa). 
3..$^{\circ}$ Otra manifestación de la idea anterior, de mayor calado, es que la argumentación me parece un tanto abigarrada, porque superpone dos caminos para alcanzar la misma conclusión. En efecto, la Sentencia no necesitaba el recurso al juicio de proporcionalidad tras el examen que había hecho anteriormente en los fundamentos sexto y séptimo, aunque, alternativamente, podía haber construido todo el razonamiento sobre el principio de proporcionalidad (fundamento octavo), lo que a mi juicio hubiera sido técnicamente más correcto. Sin embargo, no parece tener mucho sentido que se amontonen las dos vías.

$4^{\circ} .^{\circ}$ Como tampoco lo tiene que el Tribunal se empeñe en camuflar sus cambios de interpretación, que suele presentar como si fueran una simple continuación de doctrinas anteriores. La STC 42/2005 viene a revocar la doctrina "Rumasa/dos", pero formalmente no se reconoce asi 1 . La doctrina de la STC 166/1986 sobre las expropiaciones legislativas singulares en relación con la declaración de la necesidad de la ocupación de los bienes (fundamento jurídico 15) es que cuando ésta se produce por ley sobreviene «una innegable limitación de la tutela judicial en cuanto que los expropiados... se ven privados de la acción judicial que tendrían en el supuesto de que la necesidad de ocupación fuese declarada por acto administrativo". Pero ello no conlleva, de suyo, una lesión del derecho a la tutela judicial efectiva (art. 24.1 CE) o de las garantías del procedimiento expropiatorio (art. 33.3 CE) porque nada impide que el expropiado pueda reaccionar ante dicha declaración por vía de la cuestión de inconstitucionalidad o del recurso de amparo ante el Tribunal Constitucional. La nueva doctrina que introduce la STC 42/2005 es que «un acto legislativo expropiatorio sólo será constitucionalmente admisible si el control jurisdiccional que admiten las normas con rango de ley (recurso directo, cuestión y autocuestión de inconstitucionalidad; esta última, previo amparo) es suficiente, en cada caso, para brindar una tutela materialmente equivalente a la que pueda dispensar frente a un acto administrativo un Juez de lo contencioso". Y, por tanto, el Tribunal va más allá: para afirmar la constitucionalidad de una expropiación ope legis no basta ya, como se decía en la STC

9 El Tribunal Constitucional revolucionó en su día el modo de argumentar de todos los jueces en nuestro país, pero su técnica argumentativa se ha esclerosado y necesita un cambio: hace falta sentencias más concisas y precisas, que no amontonen argumentos sin criterio o de modo incoherente y que muestren con claridad cuál es la doctrina fija y cambiante del Tribunal. Es difícil no coincidir (también) en este punto con el maestro Rubio Llorente cuando repasa el "estilo" del Tribunal. Observa que su "peculiar estilo decisorio tuvo alguna justificación en los primeros tiempos del Tribunal", pero "ha degenerado en un cierto manierismo que da lugar a sentencias excesivamente largas", de "textos profusos y llenos de afirmaciones generales", "en las que se pierde las razones de la decisión". Rubio Llorente postula una sentencias "mucho más breves, más rotundas, más ceñidas al caso, más depuradas de doctrinas generales y más austeras, de manera que las consideraciones laterales no obscurecieran nunca el fundamento de la decisión" ("El Tribunal Constitucional", Revista Española de Derecho Constitucional, 71, 2004, págs. 22 s.) Me parece que sus comentarios son perfectamente aplicables a la Sentencia en examen. 
166/1986, que exista la posibilidad de acudir al Tribunal Constitucional para debatir la declaración de la necesidad de ocupación de los bienes a través de ciertos procesos, sino que estos procesos (cuestión de inconstitucionalidad, recurso de amparo) deben poder ofrecer, sin desnaturalizarlos, una "tutela materialmente equivalente" a la que dispensaría un Juez de lo contencioso.

5..$\left.^{\circ}\right)$ Pero el reparo más de fondo que quizás pueda oponerse a la STC $48 / 2005$ no es lo que dice, sino lo que no dice. Ciertamente, el nuevo test, criterio o estándar de la "tutela materialmente equivalente" viene a reducir al mínimo, con buen criterio, el ámbito legítimo de tal tipo de expropiaciones. Es altamente problemático en el futuro que pueda dictarse una ley expropiatoria de caso único que supere la nueva doctrina. Pero el Tribunal parece haber "disuelto" más que "resuelto" el problema, porque la cuestión de fondo sigue siendo la dudosa compatibilidad de dichas leyes con el derecho fundamental de propiedad. Empezando porque me parece de dudosa validez cualquier ley de caso único porque ataca el principio de igualdad (art. 14 CE) y su necesaria exigencia de "abstracción" de la ley ${ }^{10}$; y siguiendo porque la sospecha se agrava si a través de una ley de caso único se limita e incluso se llega a lesionar un derecho fundamental como es el de propiedad privada.

Sigo pensando, en efecto, que las leyes expropiatorias de caso único son radicalmente incompatibles no sólo con la garantía del procedimiento expropiatorio del art. $33.3 \mathrm{CE}$ (en relación con el derecho a la tutela judicial efectiva del art. 24.1 CE), sino también con el propio ejercicio del derecho de propiedad privada (art. $33.1 \mathrm{CE}$ ) en condiciones de igualdad (art. $14 \mathrm{CE})^{11}$. Como muy bien alegaba el Fiscal General del Estado (sin que el Tribunal Constitucional se pronunciase sobre ello), se compromete el principio de igualdad porque los expropiados mediante ley de caso único gozan de peor trato que los expropiados según el procedimiento general. Ítem más. El sentido histórico de la exigencia de la ley en la expropiación no ha sido el de facilitarla o hacerla más vulnerable a la potestad administrativa expropiatoria, sino justo el contrario, el de rodearla de mayores garantías. De ahí la especial perversión de las expropiaciones legislativas. La Constitución española no la reconoce expresamente, además (a diferencia de los modelos alemán e italiano disponibles). Es discutible su existencia también desde el principio de separación de poderes (ínsito en el

10 "Abstracción" y no "generalidad" porque no se puede discutir (y menos en el Estado social) la validez de las leyes singulares (de hecho, apenas existen leyes verdaderamente generales). El Tribunal Constitucional en ningún momento distingue (como tampoco hizo en la STC 166/1986, lo cual motivó la discrepancia del Magistrado Rubio Llorente) entre leyes expropiatorias "singulares" y leyes de caso único", que sí son, de suyo, altamente problemáticas en todo caso.

11 Ver: "La propiedad privada...", ob.cit., págs. 426-429. De nuevo, la cita a R. Parada es obligada: "Evolución y crisis del instituto expropiatorio", Documentación Administrativa, núm. 222, 1990, págs. 41 ss. 
concepto de Estado de Derecho), concretamente con el concepto de «reserva de Administración", que debe ser normalmente respetado a fin de, como se dice en la STC 166/1986, "evitar el desequilibrio institucional que conlleva la intromisión de unos de esos poderes (legislativo y gobierno) en la función propia del otro". Por otro lado, ha avanzado el consenso sobre la dificultad de su conciliación con el derecho a la tutela judicial efectiva y lo que podríamos denominar el "debido procedimiento" expropiatorio. En esta línea se ha producido el cambio de doctrina de la STC 48/2005 respecto de la STC 166/1986.

En conclusión, la STC 48/2005 ha endurecido las condiciones de las expropiaciones legislativas de caso único (sin atreverse a expulsarlas por completo de nuestro ordenamiento), pero su nueva doctrina, el criterio de la stutela materialmente equivalente", no parece estar llamada a provocar un cambio significativo en la devaluada comprensión del Tribunal sobre el derecho de propiedad privada, a pesar de ser el primer pronunciamiento en que lo ampara, eso sí, prácticamente sin citarle. Una Sentencia posterior, la 251/2006, de 25 de julio, confirma plenamente esta sospecha. En efecto, esta Sentencia resuelve una cuestión de inconstitucionalidad planteada por la Sala de lo ContenciosoAdministrativo del Tribunal Superior de Justicia de Madrid en relación con diversos preceptos de la Ley de la Comunidad de Madrid de medidas de política territorial, suelo y urbanismo (en su redacción de 1995), en cuanto establecía un determinado diseño del Jurado territorial para la fijación del justiprecio en las expropiaciones a realizar por la Comunidad Autónoma y los Ayuntamientos de su territorio que, a juicio del órgano a quo, desequilibraba en exceso su composición a favor del poder público expropiante. El Tribunal desestima la cuestión, pero hay dos votos discrepantes de los magistrados Delgado Barrio y Rodríguez Arribas. La Sentencia, como muy observa este último magistrado, conduce la cuestión hacia la facultad de autoorganización de la Comunidad Autónoma y su competencia para establecer procedimientos administrativos propios, "cuestiones que sólo lateralmente tienen que ver con la duda de constitucionalidad planteada", y no la enfoca desde el punto correcto, la protección constitucional del derecho de propiedad ${ }^{12}$.

Así pues, se puede concluir en relación con la Sentencia 48/2005 (como también se podría predicar en parte de la STC 251/2006), que ante un caso bastante claro, casi "de manual", el Tribunal Constitucional ha endurecido su interpretación sobre las expropiaciones legislativas de caso único, pero, en general, sigue confinando al derecho de propiedad privada en el arcón de los objetos perdidos del texto constitucional. Casi como si de un personaje de Samuel Beckett se tratase.

12 Y eso que la Ley madrileña ya había sido modificada posteriormente para proceder a una composición más equilibrada, desde el punto de vista de los derechos de los potenciales expropiados, del Jurado territorial. Ni siquiera actuando sobre una Ley ya no vigente la inercia del Tribunal Constitucional le lleva a amparar los derechos dominicales. 
ABSTRACT. This work analyses critically the sentence 48/2005 of the Supreme Constitutional Court of Spain. Its importance relies on the fact that this sentence is the first sentence where the Supreme Constitutional Court considers violated the constitutional right of private property and also it reduces to a more strict margins than the actual ones the institute of expropriation ope legis within Spain's legal system.

The new criterion of the "substantially equivalent protection" comes to revoke the existent doctrine of the Tribunal about legislative expropriations. But It is doubtfull that it can be interpreted as a change on the Tribunal's view to a more protective reading of the right of private property. 